\title{
COVID-19 Pandemic and Initial Psychological Responses by Bangladeshi People
}

\author{
Oli Ahmed ${ }^{1}$, Md. Zahir Ahmed ${ }^{2}$, Zhou Aibao $^{3}$, Sohan Mia ${ }^{4}$, MD. Arif Uddin Khan ${ }^{5}$
}

${ }^{1}$ Oli Ahmed, Assistant Professor, Department of Psychology, University of Chittagong, Chattogram - 4331, Bangladesh;

${ }^{2} \mathrm{Md}$ Zahir Ahmed, Doctoral Candidate, College of Psychology, Northwest Normal University, China;

${ }^{3}$ Zhou Aibao, Professor, College of Psychology, Northwest Normal University, China;

${ }^{4}$ Sohan Mia, Lecturer, Institute of Modern Languages, University of Chittagong, Chattogram 4331, Bangladesh;

${ }^{5}$ MD. Arif Uddin Khan, Assistant Professor, Department of Sociology, University of Chittagong, Chattogram - 4331, Bangladesh.

Correspondence concerning this article should be addressed to Oli Ahmed, Assistant Professor, Department of Psychology, University of Chittagong, Chattogram - 4331, Bangladesh. Email: oliahmed_polash131@cu.ac.bd 
COVID-19 Pandemic and Initial Psychological Responses by Bangladeshi People 


\begin{abstract}
The present study was aimed to investigate the causes of COVID-19 worry and its effect on initial behaviors that observed in early stage of the COVID-19 outbreak in Bangladesh. In the online survey, participants' were asked about normative concerns, COVID-19 worry, initial behaviors, and the neuroticism personality trait. Results demonstrated that (i) higher normative concerns and neurotic trait were predictors of higher COVID-19 worry; and (ii) higher normative concerns and COVID-19 worry significant predictors of buying preparatory materials, higher worry for postponing travel plan, and higher worry and neuroticism for purchasing daily commodities more than usual and difficulties in concentration.
\end{abstract}

Keywords: Pandemic; COVID-19 worry; normative concerns; neuroticism; initial behaviors. 


\section{Introduction}

Novel Coronavirus disease 2019 (COVID-19) is a rapid, human to human transmittable respiratory disease which has widespread uniformity with Severe Acute Respiratory Syndrome (SARS-CoV) as both belong to the Coronaviridae family, genus Betacoronavirus (Huang et al., 2020) believed to have originated and spread from a seafood market of Wuhan city of China (Xiang et al., 2020). The outbreak of atypical pneumonia caused unexplained first declared by the Health Commission of Hubei province on December 31, 2019. Thought COVID-19 is originated and spread from China, most of the European countries have been squandered significantly than any other countries of Asia as they exceedingly delayed in shutting down the travel facility (Penny, 2020). As of April 18, 2020, globally confirmed cases of COVID-19 is 2275783 with 156104 deaths (Worldometer, 2020 April 18). Though the epidemic emerged in China, but the crisis went beyond the specific territory and touched almost every sector. World Health Organization declared COVID-19 as a pandemic on March 11, 2020 (WHO, 2020 March 11). After the warning of $\mathrm{WHO}$ and skyrocketed number of the cases instigated researchers around the world to discover lifesaving innovation to overthrow COVID-19 (Routley, 2020) and some 35 organizations are racing to succeed (Spinney, 2020).

Though the healthcare infrastructure of Bangladesh is extremely poor as the legacy of national resource constraints, it confirmed the first case in significantly later on March 08, 2020 (IEDCR, 2020), where first confirmed death was recorded on March 18, 2020 (Khaliq \& Sakib, 2020). From the second week of April, the number of confirmed cases is increasing. Local administrations have imposed lockdown in 32 districts (out of 64 districts). As of April 18, 2020, total confirmed cases are 2144 and 84 people died (IEDCR, 2020 April 18).

Usually, emotional and behavioral responses and mental health issues remain almost untouched during such pandemic as world run after inventing medicine to cure the disease. This picture is also same in the current COVID-19 pandemic, as inadequate attempts have been taken to address mental health issues and emotional and behavioral responses. In the present study, we are trying to address the concern/worry about COVID-19 infection as an emotional response after COVID-19 positive cases confirmed in the country as "an affective and emotional response to threat" (Goodwin et al., 2011). COVID-19 worry may arise from several factors such as 
unavailability of vaccine till to date, higher rate of infection globally, lack of sufficient knowledge, etc. Besides these situational factors, some demographic factors (i.e.- gender), social context factors (i.e. group norms or group concerns about the threat), and psychological factors (i.e.- personality traits) may also affect the worry. Women were more concerned about affecting by the SARS virus than men during the SARS epidemic (Lau et al. 2007). Goodwin et al. (2011) also adapted a model where they found that personal conservation beliefs and normative concerns were significant predictors of the worry related to Swine Flu virus. Studies suggested that significant others' concerns about threat are also important predictors of the worry related to that threat (Leppin \& Aro, 2009; Pidgeon et al, 2003). Among personality traits, neuroticism has a strong association to depression, panic disorder, generalized anxiety disorder, etc (Khan et al., 2005). It is the only predictor of psychopathology, while extraversion and agreeableness for positive mental health (Lamers et al., 2012). COVID-19 worry also leads to some immediate action in everyday life as coping strategy to reduce worry. During the swine flu outbreak, Rubin et al. (2009) have found that people having higher anxiety related to swine flu were carried more avoidance behavior than people having lower anxiety. Moreover, worry during flu outbreak also has association with concentrating on daily activities (Goodwin et al., 2011; Sprang, 1999).

Although it would be said that the COVID-19 worry is the main underlying reason of the immediate behavioral and psychological response, the predictors of the COVID-19 worry are unknown as it has a different pattern of affecting than earlier flu viruses. Therefore, in the present study, we aimed to identify possible predictors (i.e. - demographic factors, normative concerns, neuroticism, etc.) of the COVID-19 worry and its consequences in immediate behaviors like buying preparatory materials (buying mask, hand sanitizer, disinfection chemicals, etc.), postponing travel plan, buying more daily commodities than usual, and difficulties in concentrating daily activities. In the present study, a hypothesized model (Figure 1) was formulated to assess the association among study variables.

\section{Methods}

\section{Participants}

In the present study, an online survey was conducted using the 'Google Form' from March 23, 2020 to March 27, 2020. An online link of the survey questionnaire was shared via 
Facebook and email. A total of 504 respondents completed online form. Among 504 participants, $284(56.3 \%)$ were male and $220(43.7 \%)$ were female and their age ranged from 18 to 60 years

old. Among them, $69.4 \%$ were students, $24.4 \%$ were full time employee, $2.2 \%$ were selfemployed and $4 \%$ were unemployed, and $77.2 \%$ had university or equivalent degree, $20.4 \%$ had completed Grade XII, and 2.2\% had other educational qualifications.

\section{Measures}

The online survey questionnaire of the present study included the neuroticism subscale of the Big Five Personality Inventory-10 (Rammstedt \& John, 2007; Bangla version: Ahmed \& Hossain, 2018), two questions about normative concerns about COVID-19 infection, two questions about COVID-19 worry, four questions about initial behavior and psychological responses, and questions about demographic information. Questions about normative concerns, COVID-19 worry, and three out of four questions about initial behavior and psychological responses adapted from the study of Goodwin et al. (2011).

The Big Five personality inventory-10 (BFPI) contains 10 items (two items for assessing each trait). This scale had acceptable test-retest reliability (.68-.83) and high correlations (.51.70) with the NEO-PI-R (Costa \& McCrae, 1992). Test - retest reliability of the neuroticism subscale in Bangla version also had good test-retest reliability (.714). This subscale had acceptable infit and outfit mean squares (.93-1.02) and non-DIF between male and female. In the present study, participants responded on a five-point Likert scale (from strongly disagree to strongly agree). These two items had significant inter-item correlation $(\mathrm{r}=.335, p<.001)$ in this study. Pallant (2016) suggested assessing inter-item correlation when there're fewer than 10 items and inter-item correlation between .2 and .4 is sufficient.

To measure normative concerns, participants were asked - "How great a risk does your family (friends) think this COVID-19 pandemic is ..." on a five point scale (from very low to very high, including don't know). These items were significantly correlated $(r=.371, p<.001)$. Regarding COVID-19 worry, participants were asked - "How concerned are you about yourself (your family members) being the victim of COVID-19 outbreak" on a four point scale (from not at all to very much) $(r=.541, p<.001)$. For assessing outcome behavior and psychological 
responses following questions were asked - (i) Have you bought anything (i.e. Masks, Hand Sanitizers, Antiseptic, etc.) in preparation for COVID-19 pandemic? (Yes/No); (ii) Have you canceled or delayed your travel plans (Yes/No); (iii) Have you brought daily commodities more than usual? (Yes/No); and (iv) How difficult has it been for you to concentrate on your daily activities or job due to COVID-19 threat you feel? (a four-point scale, from not at all to very difficult).

\section{Statistical Analysis}

In the present study, IBM SPSS version 26.0 and IBM AMOS version 24.0 were used to analyze the extracted data. Using SPSS, descriptive statistics (frequency and percentages), independent sample t-test, $\chi^{2}$ test were performed and path analysis was performed to assess the relationship among study variables using AMOS.

\section{Ethics}

The present study was carried out in accordance with the Declaration of Helsinki and its later amendments or comparable ethical standards as the data were collected from human participants. This study was approved by the university ethics committee of the Northwest Normal University, China (IRB no.- 20200018). Participants were informed about the study purposes, its nature, and required time to complete, cost and benefits, and confidentiality of information at the beginning of the survey. After reading above information, they had to express their opinion to participate in the study by clicking either 'Yes' or 'No'.

\section{Results}

Table 1 shows that, $50.2 \%$ participants rated that their family members and $47.4 \%$ rated that their friends judge the risk of the COVID-19 infection to be 'very high'. Regarding worry, $35.9 \%$ participants rated that they were 'very much' worried about themselves to be a victim of COVID-19 virus and 58.5\% were 'very much' worried about their family members to be victims. Almost all participants (97.6\%) bought or planned to buy preparatory materials (i.e. masks, hand sanitizers, soap, etc.). Among participants, 83.3\% participants postponed their travel plans due to COVID-19 hit in the country and $39.5 \%$ participants brought necessary daily commodities more than usual. Twenty three percent participants rated that they felt very much difficulties to 
concentrate on their daily activities due to the COVID-19 worry. Table 2 and 3 shows nonsignificant gender differences in normative concerns ( $t$-value $=-.427, p=.671$, effect size $=$ $.039)$, worry $(t$-value $=-1.799, p=.073$, effect size $=.16)$, purchasing preparatory materials $\left(\chi^{2}=\right.$ $3.64, p=.056$, effect size $=.085)$, postponing travel $\left(\chi^{2}=1.87, p=.172\right.$, effect size $\left.=.061\right)$, buying daily commodities more than usual $\left(\chi^{2}=3.47, p=.067\right.$, , effect size $\left.=.083\right)$, and difficulties in concentration due to COVID-19 worry ( $t$-value $=1.73, p=.085$, effect size $=.039$ ).

Due to non-significant gender differences among study variables, gender was excluded from the path analysis model. Model fit statistics of the path analysis suggested that the hypothesized model had good fits $\left(\chi^{2}=24.214, d f=7, \chi^{2} / d f=3.459, p=.001, \mathrm{GFI}=.986, \mathrm{CFI}=.972\right.$, TLI=.917, RMSEA=.070, LO $90=.041$ and HI $90=.101, \mathrm{p}$ close $=.120, \mathrm{SRMR}=.035)$. The results of the path analysis (Figure 2) showed that both normative concerns about the COVID-19 $(\beta=.326, p<.001)$ and neuroticism $(\beta=.341, p<.001)$ significant predictors of COVID-19 worry. Both normative concerns and neuroticism predicted 22\% variance of COVID-19 worry. Normative concerns, neuroticism, and COVID-19 worry predicted $16 \%$ variance of the buying preparatory materials, $22 \%$ of travel plan, $26 \%$ of buying daily commodities more than usual, and $20 \%$ of concentration problem due to COVID-19 threat. Among variables, normative concerns $(\beta=.107, p=.014)$ and COVID-19 worry $(\beta=.362, p<.001)$ significant predictors of buying preparatory materials. Postponing travel plan significantly predicted by COVID-19 worry ( $\beta=.449, p<.001)$, buying daily commodities more than usual significantly predicted by neuroticism $(\beta=.281, p<.001)$ and COVID-19 worry $(\beta=.321, p<.001)$, and difficulties in concentration was significantly predicted by neuroticism $(\beta=.126, p=.003)$ and COVID-19 worry $(\beta=.358, p<.001)$.

\section{Discussion}

Despite of the modernization in all sectors, the outbreak of infectious diseases and subsequent epidemics are propagating all over the world as the humans are spreading significantly (LePan, 2020 March 14). The human-to-human transmission feature and continuous mutation into a more deadly strain worsen the contagion (Cascella et al., 2020). Due to the COVID-19 pandemic, worry has touched almost all the people across the globe. In this study, we identified the some causes of the COVID-19 worry and immediate consequence after confirming first COVID-19 positive case in Bangladesh. Results showed that almost all participants' family 
and friends perceive higher risk of COVID-19 infection. Almost all participants' also highly worried about being COVID-19 victim. This study has collected research data from Bangladesh at the early stage of COVID-19 outbreak with very nominal confirmed cases and reported death, though by that time the world has already been grappled. People have already come to know the severity of the COVID-19 pandemic in China, Italy, Spain, USA, etc. Moreover, a large of number of people has returned from COVID-19 affected countries and most of them didn't follow authority's instruction to maintain home-quarantine for 14 days. Therefore, higher concern regarding the COVID-19 threat is usual among people. This study suggested that close others concerns about a potential threat was the predictor of the personal worry of that threat. Goodwin et al. (2011) also have suggested a similar association between normative concerns about swine flu outbreak and personal worry about it.

Besides, this study also suggested that people higher in neuroticism trait were more worried about COVID_19 threat. Usually, people with higher neurotic traits are characterized through having low self-esteem, irrational perfectionistic beliefs, and pessimistic attitude (MaCrae \& Costa, 2008) and they are more sensitive to negative affect (Suls \& Martin, 2005). Significantly, neuroticism leads the poor stress management, perceive minor frustration as overwhelmed depression, and surprisingly interpreting an ordinary crisis as a great threat (Widiger \& Oltmanns, 2017). The quality of life of a neurotic individual is with elevated level of ill-will feeling, excessive worry and other occupational failure (Ozer \& Benet-Martínez, 2006). But the maladjustment often motivates the cognition; perform exceptionally well, especially when the situation requires caution, and discipline to act effectively to the anticipated threat (Bendersky \& Shah, 2013). These findings regarding the underlying causes of COVID-19 worry have a great practical implication for mental health practitioners and other concerned authority for effective dealing with psychologically vulnerable persons due to COVID-19 worry. From personal observation of the authors, a large number of people are not concerned about the severity of COVID-19 pandemic due to lack of literacy, misleading information from some religious leaders and some YouTube channels and Facebook pages, groups. Government is facing difficulties to make conscious these people about the pandemic. Findings about the causes of COVID-19 worry would helpful to local administration and law enforcing agencies to analyze why these people are not concerned and what measure they can take. 
Study findings showed that higher personal and close others' safety concern lead to purchase protective materials. People postponed travel plans and purchasing extra daily commodities than usual due to personal anxiety about the COVID-19 threat. People don't know how many days the pandemic will be in Bangladesh. As most of the factories are closed as part of the first line protective measure during an epidemic, people are uncertain about the supplies of the daily commodities. Such uncertainty about future food supplies might also be worked beside neuroticism and worry to purchase extra commodities. Neuroticism and COVID-19 worry also has significant association to problem in concentrating on daily activities. The unremitting threat of COVID-19 is interrupting the daily activities with psychological symptoms (APA, 2020 April 6). Wang et al. (2020) have found that highly worried about the likelihood of family members to be COVID-19 infected leads to higher stress. This epidemic induced stress predicts behavioral change in different negative forms, including attention deficit and concentration difficulty (CDC, 2020).

\section{Limitations}

The present study had several limitations. This survey was conducted using online tool 'Google Form' as it was impossible to conduct face-to-face interviews for data collection. So, people who read well and having internet access were participated in this study. A large portion of Bangladeshi people is out of Internet access. Besides, the majority of the respondents were graduate level students. Therefore, representativeness of the study sample was in questions. Data in this study were self-reported which might be subjected to social desirability bias as COVID-19 pandemic has got huge attention across the world.

\section{Recommendations}

As the present study suggested that, almost all respondents were worried about COVID19 infection, it is urgent to assess the severity of psychological problems (anxiety, depression, stress etc.) and well-being of Bangladeshi people. It is important to reduce the amount of time spent on social media as it negatively affects user's mental health with rapid spread of rumors and trigger negative emotions. To render mental health support during emergency situation, Bangladeshi government should prepare comprehensive guideline where telephone and web 
based counseling need to integrate instantaneously. Since majority of the infected are front-line warriors i.e. doctor, police, and administrators so government should employ intensive mental health service for them.

\section{Conclusions}

The outbreak of CIVID-19 has been increasing the psychological problems among the Bangladeshi people significantly ever since the initial stage. Our findings suggest that the emotional aspects, worry and normative concerns, are significantly predicting the behavioral responses. This emotional concern often widely depends on the neuroticism where excessive worry and other psychological problems predict the precautionary behavior with the purchase pattern. Our study recommends to cautious and reduced use of social media, rendering telephone based mental health services, appoint psychologists and psychiatrists for front-line warriors in the war against COVID-19, and preparing a guideline for offering mental health services.

Acknowledgement: We are thankful to Mr. Mohammad Mohibul Hasan, Technical Officer, Friendship (NGO), Ms. Syeda Jannatun Nayeem Siddiqua, Ex-student, Depratment of Psychology, University of Chittagong, Ms._Moslima Akter, Graduate student, Depratment of Psychology, University of Chittagong, Mr. Md. Zahid Ahamed Ratul, and Mr. Abdullah Mursalin Utshow for their cordial cooperation to conduct the online survey.

Funding: No funding.

Declaration of Conflicting Interest: No potential competing interest was reported by the authors.

\section{References}

Ahmed, M. Z., Ahmed, O., Aibao, Z., Hanbin, S., Siyu, L., \& Ahmad, A. (2020). Epidemic of COVID-19 in China and Associated Psychological Problems. Asian Journal of Psychiatry, 51, 102092. doi: 10.1016/j.ajp.2020.102092

Ahmed, O., \& Hossain, M. A. (2018). The translated Bangla version of the Big Five Inventory10. Unpublished Manuscript, Department of Psychology, University of Chittagong, Chattogram, Bangladesh. 
APA. (2020, April 6). Finding local mental health resources during the COVID-19 crisis. Retrieved from https://www.apa.org/topics/covid-19/local-mental-health

Bendersky, C., \& Shah, N. P. (2013). The Downfall of Extraverts and Rise of Neurotics: The Dynamic Process of Status Allocation in Task Groups. Academy of Management Journal, 56(2), 387-406. doi:10.5465/amj.2011.0316

Cascella, M., Rajnik, M., Cuomo, A., Dulebohn, S. C., \& Napoli, R. D. (2020). Features, Evaluation and Treatment Coronavirus (COVID-19) [Updated 2020 Mar 20]. Treasure Island (FL): $\quad$ StatPearls $\quad$ Publishing. $\quad$ Retrieved from https://www.ncbi.nlm.nih.gov/books/NBK554776/

CDC. (2020). Stress and Coping. Retrieved from https://www.cdc.gov/coronavirus/2019$\underline{\text { ncov/daily-life-coping/managing-stress-anxiety.html }}$

Costa, P. T., \& McCrae, R. R. (1992). NEO-PI-R professional manual. Odessa, FL: Psychological Assessment Resources.

Goodwin, R., Gaines, S. O., Myers, L., \& Neto, F. (2011). Initial Psychological Responses to Swine Flu. International Journal of Behavioral Medicine, 18(2), 88-92. doi:10.1007/s12529-010-9083-Z

Huang, C., Wang, Y., Li, X., Ren, L., Zhao, J., Hu, Y., ... Cao, B. (2020). Clinical features of patients infected with 2019 novel coronavirus in Wuhan, China. The Lancet, 395(10223), 497-506. doi:10.1016/s0140-6736(20)30183-5

IEDCR. (2020, April 18). Date wise COVID-19 case. Retrieved 20 from https://www.iedcr.gov.bd/

Khaliq, R., \& Sakib , S. M. N. (2020, March 18). Bangladesh confirms first death from new coronavirus South Asian country reports 14 cases of deadly infection so far. Anadolu Agency. Retrieved from https://www.aa.com.tr/en/asia-pacific/bangladesh-confirms-firstdeath-from-new-coronavirus/1770315\#

Khan, A. A., Jacobson, K. C., Gardner, C. O., Prescott, C. A., \& Kendler, K. S. (2005). Personality and comorbidity of common psychiatric disorders. British Journal of Psychiatry, 186(03), 190-196. doi:10.1192/bjp.186.3.190

Lamers, S. M. A., Westerhof, G. J., Kovács, V., \& Bohlmeijer, E. T. (2012). Differential relationships in the association of the Big Five personality traits with positive mental health 
and psychopathology. Journal of Research in Personality, 46(5), 517-524. doi:10.1016/j.jrp.2012.05.012

Lau, J. T. F., Kim, J. H., Tsui, H. Y., \& Griffiths, S. (2007). Anticipated and current preventive behaviors in response to an anticipated human-to-human H5N1 epidemic in the Hong Kong Chinese general population. BMC Infectious Diseases, 7(18). doi:10.1186/1471-2334-7-18

LePan, N. (2020, March 14). Visualizing the History of Pandemics. Retrieved from https://www.visualcapitalist.com/history-of-pandemics-deadliest/

Leppin, A., \& Aro, A. R. (2009). Risk Perceptions Related to SARS and Avian Influenza: Theoretical Foundations of Current Empirical Research. International Journal of Behavioral Medicine, 16(1), 7-29. doi:10.1007/s12529-008-9002-8

McCrae, R. R., \& Costa, P. T., Jr. (2008). A five-factor theory of personality. In O.P. John, R.W. Robins, \& L.A. Pervin, Handbook of personality: Theory and research (pp. 159-181). New York: Guilford.

Ozer, D. J., \& Benet-Martínez, V. (2006). Personality and the Prediction of Consequential Outcomes. Annual Review of Psychology, 57(1), 401-421. Doi: 10.1146/annurev.psych.57.102904.190127

Pallant, J. (2016). SPSS survival manual: A step by step guide to data analysis using IBM SPSS. Maidenhead: McGraw Hill Education.

Penney, J. (2020, April 2). Coronavirus Started in China, but Europe Became the Hub for Its Global Spread. The Intercept. Retrieved from https://theintercept.com/2020/04/02/coronavirus-europe-travel/

Pidgeon, R. E., Kasperson, R. E., \& Slovic, P. (2003). The social amplification of risk. Cambridge: Cambridge University Press.

Rahman, M., \& Ahmed, O. (2018). Facebook use, Facebook addiction, and mental health of Chittagong university students. Bulgarian Journal of Science and Education Policy, 12(2), 345-358.

Rammstedt, B., \& John, O. P. (2007). Measuring personality in one minute or less: A 10-item short version of the Big-Five Inventory in English and German. Journal of Research in Personality, 41(1), 203-212. doi: 10.1016/j.jrp.2006.02.001 
Routley, N. (2020, April 1). Every Vaccine and Treatment in Development for COVID-19, So Far. Visual Capitalist. Retrieved from https://www.visualcapitalist.com/every-vaccinetreatment-covid-19-so-far/

Rubin, G. J., Amlot, R., Page, L., \& Wessely, S. (2009). Public perceptions, anxiety, and behaviour change in relation to the swine flu outbreak: cross sectional telephone survey. BMJ, 339, b2651. doi:10.1136/bmj.b2651

Spinney, L. (2020, April 3). When will a coronavirus vaccine be ready? The Guardian. Retrieved from https://www.theguardian.com/world/2020/apr/03/when-will-a-coronavirus$\underline{\text { vaccine-be-ready }}$

Sprang, G. (1999). Post-Disaster Stress Following the Oklahoma City Bombing: An Examination of Three Community Groups. Journal of Interpersonal Violence, 14(2), 169-183. doi: $10.1177 / 088626099014002005$

Suls, J., \& Martin, R. (2005). The Daily Life of the Garden-Variety Neurotic: Reactivity, Stressor Exposure, Mood Spillover, and Maladaptive Coping. Journal of Personality, 73(6), 1485-1510. doi:10.1111/j.1467-6494.2005.00356.x

Wang, C., Pan, R., Wan, X., Tan, Y., Xu. L., Ho, C.S., \& Ho, R.C. (2020). Immediate psychological responses and associated factors during the initial stage of the 2019 coronavirus disease (COVID-19) epidemic among the general population in China. International Journal of Environmental Research and Public Health, 17, 1729. doi:10.3390/ijerph17051729

WHO (2020, March 11). WHO Director-General's opening remarks at the media briefing on COVID-19 - 11 March 2020. Retrieved from https://www.who.int/dg/speeches/detail/whodirector-general-s-opening-remarks-at-the-media-briefing-on-covid-19---11-march-2020.

Widiger, T. A., \& Oltmanns, J. R. (2017). Neuroticism is a fundamental domain of personality with enormous public health implications. World Psychiatry, 16(2), 144-145. doi:10.1002/wps.20411

Worldmeters. (2020, April 18). COVID-19 Coronavirus Pandemic. Retrieved from https://www.worldometers.info/coronavirus/

Xiang, Y.-T., Yang, Y., Li, W., Zhang, L., Zhang, Q., Cheung, T., \& Ng, C. H. (2020). Timely mental health care for the 2019 novel coronavirus outbreak is urgently needed. The Lancet Psychiatry, 7(3), 228-229. doi:10.1016/s2215-0366(20)30046-8 
COVID-19 PANDEMIC AND INITIAL RESPONSES

Tables

Table 1: Frequency and percentages of responses in questions regarding normative concerns, COVID-119 worry, and initial behavioral responses

\begin{tabular}{|c|c|c|}
\hline Questions & Response category & $f(\%)$ \\
\hline How great a risk does your family think this COVID-19 & High & $210(41.7 \%)$ \\
\hline pandemic is..? & Very high & $253(50.2 \%)$ \\
\hline How great a risk do your friends think this COVID-19 & High & $222(44.0 \%)$ \\
\hline pandemic is..? & Very high & $239(47.4 \%)$ \\
\hline How concerned are you about yourself being the victim & Concerned & $220(43.7 \%)$ \\
\hline of COVID-19 outbreak? & Very much concerned & $181(35.9 \%)$ \\
\hline How concerned are you about your family members & Concerned & $150(29.8 \%)$ \\
\hline being the victim of COVID-19 outbreak? & Very much concerned & $295(58.5 \%)$ \\
\hline Have you brought anything (i.e. Masks, Hand Sanitizers, & No & $12(2.4 \%)$ \\
\hline Antiseptic, etc.) in preparation for COVID-19 pandemic? & Yes & $492(97.6 \%)$ \\
\hline \multirow[t]{2}{*}{ Have you canceled or delayed your travel plans (Yes/No) } & No & $84(16.7 \%)$ \\
\hline & Yes & $420(83.3 \%)$ \\
\hline \multirow[t]{2}{*}{ Have you brought daily commodities more than usual? } & No & $305(60.5 \%)$ \\
\hline & Yes & $199(39.5 \%)$ \\
\hline How difficult it has been for you to concentrate on your & Difficult & $193(38.3 \%)$ \\
\hline daily activities or job due to COVID-19 threat you feel? & Very much difficult & $118(23.4 \%)$ \\
\hline
\end{tabular}


COVID-19 PANDEMIC AND INITIAL RESPONSES

Table 2: Gender differences in normative concern, COVID-19 worry, and concentration on daily activities $($ Male $=284$, Female $=220)$

\begin{tabular}{llllccc}
\hline Variable & Groups & M & SD & t-value & Sig. & Cohen's d \\
\hline Normative concern & Male & 6.70 & 1.27 & -.427 & .671 & .039 \\
& Female & 6.75 & 1.31 & & & \\
\hline COVID-19 worry & Male & 6.51 & 1.33 & -1.78 & .073 & .16 \\
& Female & 6.72 & 1.24 & & & \\
\hline Concentration on daily & Male & 2.85 & .86 & 1.73 & .085 & .16 \\
activities & Female & 2.71 & .88 & & & \\
\hline
\end{tabular}


Table 3: Gender differences in purchasing preparatory materials, postpone travel plan, and purchasing daily commodities after confirming COVID-19 positive cases in Bangladesh

\begin{tabular}{llccccc}
\hline Variable & Response & \multicolumn{2}{c}{ Gender } & $\chi^{2}$ & Sig. & Effect \\
\cline { 3 - 5 } & Categories & Male & Female & & & size \\
\hline Purchasing & No & $10(3.5 \%)$ & $2(.9 \%)$ & 3.64 & .056 & .085 \\
preparatory materials & Yes & $274(96.5 \%)$ & $218(99.1 \%)$ & & & \\
\hline Postpone travel plan & No & $53(18.7 \%)$ & $31(14.1 \%)$ & 1.87 & .172 & .061 \\
& Yes & $231(81.3 \%)$ & $189(85.9 \%)$ & & & \\
\hline Purchasing daily & No & $182(64.1 \%)$ & $123(55.9 \%)$ & 3.47 & .067 & .083 \\
commodities more & Yes & $102(35.9 \%)$ & $97(44.1 \%)$ & & & \\
than usual & & & & & & \\
\hline
\end{tabular}


Figure

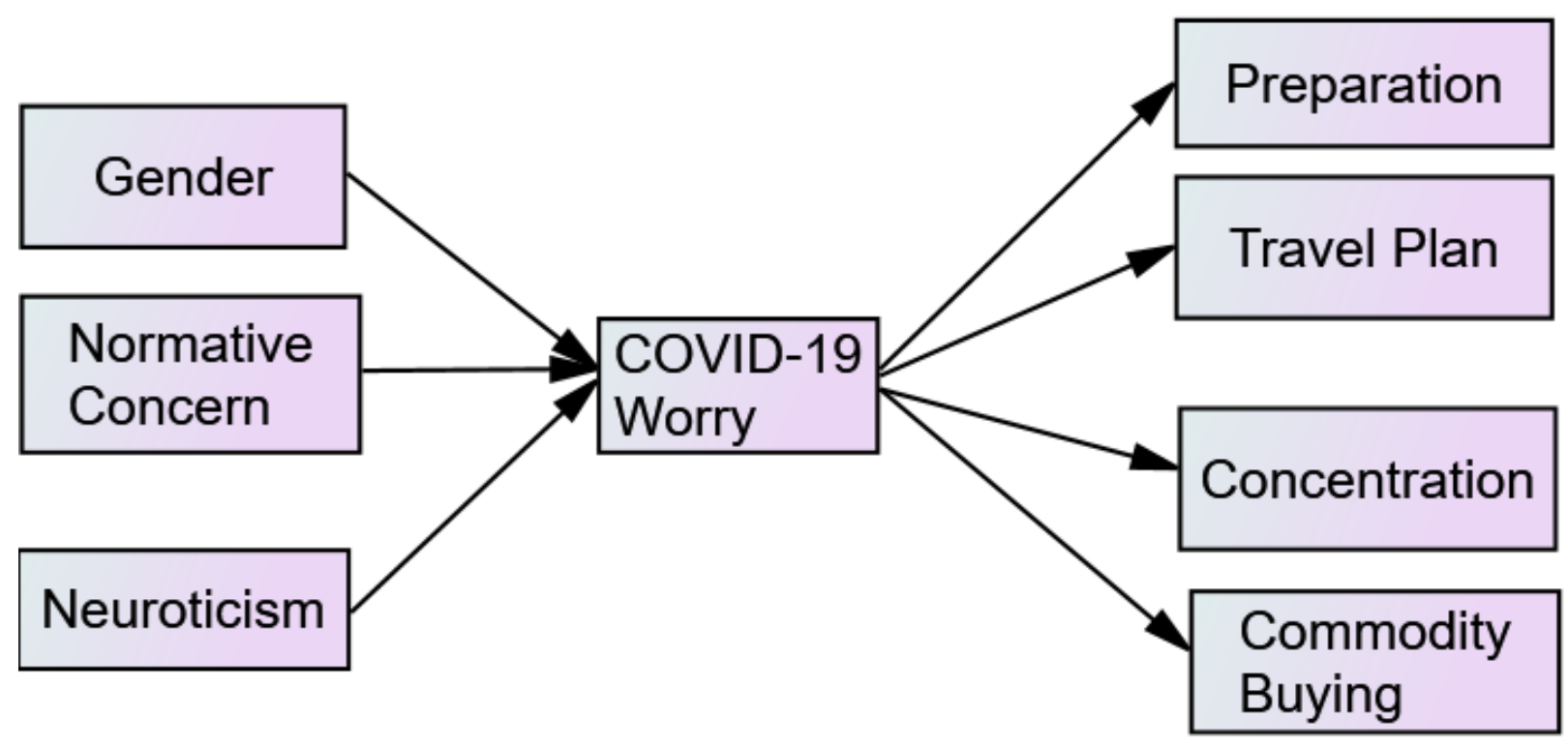

Figure 1: The structural model about the association among study variables. 


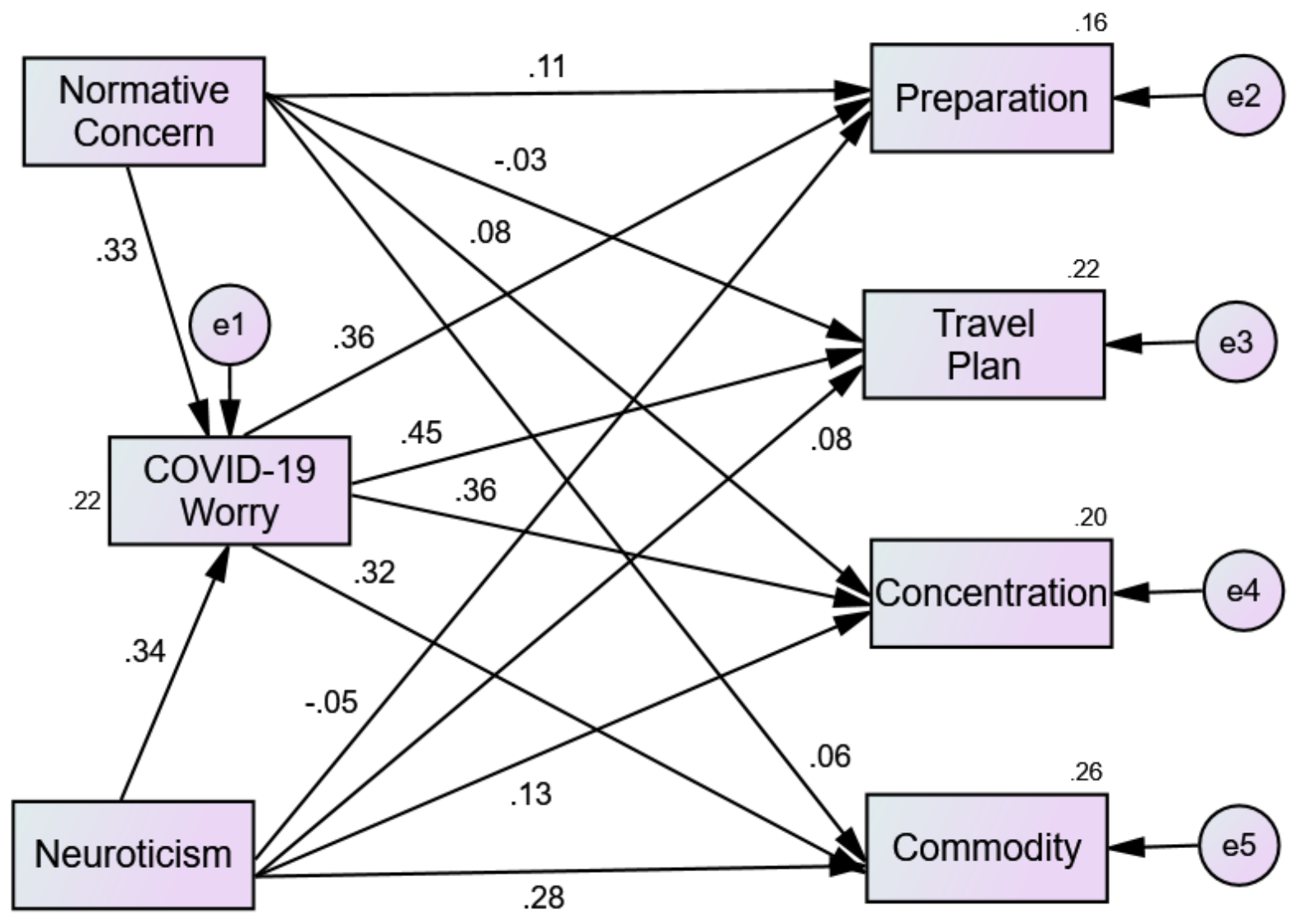

Figure 2: Path analysis of COVID-19 worry and its causes and consequence on initial responses. 